\title{
The essential two-component regulatory system encoded by yycF and yycG modulates expression of the ftsAZ operon in Bacillus subtilis
}

\author{
Keisuke Fukuchi, Yasuhiro Kasahara, Kei Asai, Kazuo Kobayashi, \\ Shigeki Moriya and Naotake Ogasawara
}

Department of Cell Biology, Graduate School of Biological Sciences, Nara Institute of Science and Technology, 8916-5, Takayama, Ikoma, Nara 630-0101, Japan

\author{
Author for correspondence: Naotake Ogasawara. Tel: +81743 72 5430. Fax: +81 743725439 \\ e-mail: nogasawa@bs.aist-nara.ac.jp
}

Essential two-component systems are now being identified in bacteria. The Bacillus subtilis yycF gene encoding a response regulator, and its orthologue in Staphylococcus aureus, were reported recently to be essential for cell growth, although genes under their control have yet to be identified. The essential nature of the yycF regulator gene and its cognate kinase gene, yycG, in $B$. subtilis was also noted during the course of construction of a knockout mutant bank of newly identified genes in the genome sequence project. It was found that yycG could be deleted in the presence of an active form of the YycF protein, thereby suggesting direct interaction between YycG and YycF. Production of mini-cells and reduction in cell length occurred when the YycF regulator was overproduced in $B$. subtilis. These observations led to the finding that YycF overproduction up-regulated the expression from the P1 promoter of the cell division operon, ftsAZ. In addition, the YycF protein binds to the P1 promoter region in vitro. These results clearly indicate that the essential two-component regulatory system encoded by yycF and yycG genes has the potential to modulate expression of the ftsAZ operon in B. subtilis.

Keywords: YycFG esssential two-component system, Bacillus subtilis, two-component regulatory system, fts $A Z$ gene

\section{INTRODUCTION}

The two-component signal-transduction system is a ubiquitous mechanism for sensing and responding to various environmental stimuli in bacteria (Parkinson \& Kofoid, 1992). This system also plays an important role in lower eukaryotes and plants (Loomis et al., 1998). A typical two-component system consists of two protein components: sensor kinase and response regulator. The sensor kinases monitor environmental signals, and modulate functions of response regulators through phosphotransfer reactions. In many cases, the response regulators modulate gene expression directly as a transcriptional repressor or activator. The two-component system can mediate diverse cellular processes, including adaptation to osmolarity, the redox state, turgor pressure, availability of nutrients, etc. The system enables genetic networks to adapt and survive in specific

Abbreviations: DAPI, 4',6-diamidino-2-phenylindole; DIG, digoxigenin. environmental conditions and is dispensable for growth under usual conditions of culture. However, essential two-component systems are now being identified in bacteria. In Caulobacter crescentus, the CrtA response regulator acts directly at cell cycle-regulated promoters to control DNA replication, DNA methylation and flagellar biogenesis, and is essential for growth (Quon et al., 1996). An essential sensor kinase, CckA, that is responsible for the CtrA activation has been identified (Jacobs et al., 1999). Furthermore, the Bacillus subtilis $y y c F$ gene and its orthologue in Staphylococcus aureus encode a response regulator and seem to be essential for cell growth, although genes under their control have yet to be identified (Fabret \& Hoch, 1998; Martin et al., 1999).

We also found the essential nature of the $y y c F G$ genes in B. subtilis during construction of a knockout mutant bank of newly identified genes by genome sequencing. The entire genome sequence of $B$. subtilis revealed the existence of over 4000 ORFs, two-thirds of which had 
not been characterized in previous genetic and biochemical studies (Kunst et al., 1997). Systematic analysis of functions of uncharacterized genes is being carried out in two research consortia, one in Japan and the other in Europe (Ogasawara, 2000). The main approach to assessing gene function is the construction of mutants in target genes and the analysis of the mutant phenotypes. Our group sequenced a $220 \mathrm{~kb}$ region containing the replication origin and identified 134 new genes (Ogasawara et al., 1994; Kasahara et al., 1997). When we carried out systematic knockout mutagenesis of the 134 genes, several genes were difficult to disrupt; these included two-component sensor kinase and regulator genes, $y y c F$ and $y y c G$. Growth of the mutants in which an IPTG-inducible promoter, Pspac, regulates the expression of $y y c F G$ became IPTG dependent. We now report that in B. subtilis expression of a cell division gene, $f t s Z$, is potentially under the direct control of the YycFG system.

\section{METHODS}

Bacterial strains, plasmids and culture conditions. The bacterial strains and plasmids used in this study are listed in Tables 1 and 2. Bacterial strains were grown in LB medium $\left(5\right.$ g yeast extract $\left.\mathrm{l}^{-1}, 10 \mathrm{~g}_{\text {tryptone }}{ }^{-1}, 5 \mathrm{~g} \mathrm{NaCl}^{-1}, \mathrm{pH} 7 \cdot 2\right)$ at $37^{\circ} \mathrm{C}$. A sporulation medium (DS medium; Schaeffer et al., 1965) was used for B. subtilis sporulation. When required, antibiotics were added at the following concentrations:

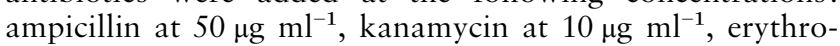
mycin at $0.5 \mu \mathrm{g} \mathrm{ml}^{-1}$, chloramphenicol at $5 \mu \mathrm{g} \mathrm{ml}^{-1}$. IPTG was added at $1 \mathrm{mM}$.

Construction of plasmids and B. subtilis strains. Table 2 summarizes relevant characteristics of the plasmids we constructed. The primers for PCR amplification of B. subtilis chromosomal fragments used to construct the plasmids are listed in Table 3. Derivatives of pMutinT3 (Vagner et al., 1998) were used to construct knockout or conditional-null mutants of B. subtilis genes. The BamHI-SacI fragment of pMutinT3 was cloned into the BamHI-SacI site of pDL (Yuan \& Wong, 1995) to obtain pDL2, which was used to place the promoter-lacZ fusions in the amyE locus of the B. subtilis genome. Plasmids pRB373 (Bruckner, 1992) and pET15b (Novagen) were used to express the $\mathrm{YycF}$ proteins in $B$. subtilis and Escherichia coli, respectively. Site-directed PCR mutagenesis was done to introduce a point mutation in the $y y c F$ gene on pRBYycF. Two primers, FKR021 and FKF022, having one base change which replaces the Asp-54 of the YycF protein with His, were designed, and the $5^{\prime}$ - and $3^{\prime}$-areas of $y y c F$ were amplified, using primer sets FKF021-FKR021 and FKF022-FKR022, respectively. The two fragments were ligated by PCR with FKF021 and FKR022 primers, and cloned into pRB373 to obtain pRBYycFD54H. Transformation of $B$. subtilis cells to obtain the strains described in Table 1 was done as described by Moriya et al. (1998). Further details of the construction of the plasmids and the B. subtilis strains used in this work are available on request.

\section{Table 1. Bacterial strains}

\begin{tabular}{|c|c|c|}
\hline Strain & Genotype & Source or reference \\
\hline \multicolumn{3}{|l|}{ B. subtilis } \\
\hline 168 & $\operatorname{trp} C 2$ & Pasteur stock \\
\hline NIS8033 & $\operatorname{trp} C 2$ yycF::pKF011(Pspac-yycFG erm) & pKF011 $\rightarrow 168$ \\
\hline NIS8032 & $\operatorname{trp} C 2$ yycG::pKF012(Pspac-yycG erm) & pKF012 $\rightarrow 168$ \\
\hline MO566 & trpC2 pheA1 amyE: :ftsAZ P1-lacZ cat & P. Stragier* \\
\hline MO685 & trpC2 pheA1 amyE: :ftsAZ P2-lacZ cat & P. Stragier \\
\hline MO531 & trpC2 pheA1 amyE: :ftsAZ P3-lacZ cat & P. Stragier \\
\hline MO1097 & trpC2 pheA1 amyE: :ftsAZ P123-lacZ cat & P. Stragier \\
\hline NIS5001 & $\operatorname{trp} C 2$ amyE: :ftsAZ P1-lacZ cat & $168+\mathrm{MO} 566$ \\
\hline NIS5002 & $\operatorname{trp} C 2$ amyE::ftsAZ P2-lacZ cat & $168+\mathrm{MO} 685$ \\
\hline NIS5003 & $\operatorname{trp} C 2$ amyE::ftsAZ P3-lacZ cat & $168+$ MO531 \\
\hline NIS5004 & $\operatorname{trp} C 2$ amyE::ftsAZ P123-lacZ cat & $168+$ MO1097 \\
\hline NIS5005 & $\operatorname{trp} C 2$ amyE: $:$ fts AZ P1(-138 to + 30)-lacZ cat & pKF101 $\rightarrow$ p168 \\
\hline NIS5006 & $\operatorname{trp} C 2$ amyE::ftsAZ P1(-130 to +30)-lacZ cat & pKF102 $\rightarrow$ p168 \\
\hline NIS5007 & $\operatorname{trp} C 2$ amyE::ftsAZ P1(-118 to +30)-lacZ cat & pKF103 $\rightarrow$ p168 \\
\hline NIS5008 & $\operatorname{trp} C 2$ amyE: $:$ ftsAZ P1(-108 to +30)-lacZ cat & pKF104 $\rightarrow$ p168 \\
\hline NIS5009 & $\operatorname{trp} C 2$ amyE: :ftsAZ P1(-92 to +30)-lacZ cat & pKF105 $\rightarrow$ p168 \\
\hline NIS5010 & $\operatorname{trp} C 2$ amyE::ftsAZ P1 $(-77$ to +30$)-$ lacZ cat & pKF106 $\rightarrow$ p168 \\
\hline NIS5011 & $\operatorname{trp} C 2$ amyE::ftsAZ $\mathrm{P} 1(-59$ to +30$)-$ lacZ cat & pKF107 $\rightarrow$ p168 \\
\hline NIS5012 & $\operatorname{trp} C 2$ amyE::ftsAZ $\mathrm{P} 1(-45$ to +30$)-$ lacZ cat & pKF108 $\rightarrow$ p168 \\
\hline \multicolumn{3}{|l|}{ E. coli } \\
\hline C600 & supE44 hsdR thi-1 thr-1 leuB6 lacY1 tonA21 & Laboratory stock \\
\hline $\mathrm{DH} 5 \alpha$ & $\begin{array}{l}\text { supE44 } \Delta l a c \mathrm{U} 169(\phi 80 \mathrm{lac} Z \Delta \mathrm{M} 15) \text { hsdR17 recA1 } \\
\text { endA1 glrA96 thi-1 relA1 }\end{array}$ & Takara \\
\hline BL21(DE3)pLysS & $\begin{array}{l}\mathrm{F}^{-} \text {ompT hsd } S_{\mathrm{B}}\left(\mathrm{r}_{\mathrm{B}}^{-} \mathrm{m}_{\mathrm{B}}^{-}\right) \text {gal dcm } \\
\quad \Delta(\operatorname{srl}-\text { recA }) 306:: \operatorname{Tn} 10(\mathrm{DE} 3) \mathrm{pLysS}\end{array}$ & Novagen \\
\hline
\end{tabular}

*P. Stragier, Institut de Biologie Physico-Chimique, Paris, France. 
Table 2. Plasmids constructed in this study

\begin{tabular}{|c|c|c|c|}
\hline Plasmid & Vector & Inserts* & Primers $\dagger$ \\
\hline pKF001 & pMutinT3 & $234 \mathrm{bp}$ internal fragment of $y y c F$ (24 to 257) & FKF001, FKR001 \\
\hline pKF002 & pMutinT3 & 487 bp internal fragment of $y y c G$ ( 24 to 510 ) & FKF002, FKR002 \\
\hline pKF003 & pMutinT3 & $425 \mathrm{bp}$ internal fragment of $y y c H$ (23 to 447$)$ & FKF003, FKR003 \\
\hline pKF004 & pMutinT3 & 349 bp internal fragment of $y y c I$ (23 to 371$)$ & FKF004, FKR004 \\
\hline pKF005 & pMutinT3 & 360 bp internal fragment of $y y c J$ (17 to 377 ) & FKF005, FKR005 \\
\hline pKF006 & pMutinT3 & $526 \mathrm{bp}$ internal fragment of $y y x A$ (10 to 555$)$ & FKF006, FKR006 \\
\hline pKF011 & pMutinT3 & $\begin{array}{l}337 \mathrm{bp} \text { fragment containing the SD sequence } \\
\text { and initiation codon of } y y c F(-80 \text { to } 257)\end{array}$ & FKF011, FKR001 \\
\hline pKF012 & pMutinT3 & $\begin{array}{l}539 \mathrm{bp} \text { fragment containing the SD sequence } \\
\text { and initiation codon of } y y c G(-29 \text { to } 510)\end{array}$ & FKF012, FKR002 \\
\hline pRBYycF & pRB373 & $\begin{array}{l}1046 \text { bp fragment covering the promoter region } \\
\text { and the entire coding region of } y y c F(-330 \text { to } \\
711)\end{array}$ & FKF021, FKR022 \\
\hline \multirow{2}{*}{\multicolumn{2}{|c|}{ pRBYycFD54H pRB373 }} & $1046 \mathrm{bp}$ fragment covering the promoter region & FKF021, FKR021 \\
\hline & & $\begin{array}{l}\text { and the entire coding region of } y y c F(-330 \text { to } \\
711) \text { having one base change that replaces the } \\
\text { Asp- } 54 \text { by His }\end{array}$ & FKF022, FKR022 \\
\hline pKF101 & pDL2 & -138 to +30 region of $f t s Z A$ P1 & FKF101, FKR101 \\
\hline pKF102 & pDL2 & -130 to +30 region of $f t s Z A$ P1 & FKF102, FKR101 \\
\hline pKF103 & pDL2 & -118 to +30 region of $f t s Z A P 1$ & FKF103, FKR101 \\
\hline pKF104 & pDL2 & -108 to +30 region of ftsZA P1 & FKF104, FKR101 \\
\hline pKF105 & pDL2 & -92 to +30 region of $f t s Z A$ P1 & FKF105, FKR101 \\
\hline pKF106 & pDL2 & -77 to +30 region of $f t s Z A$ P1 & FKF106, FKR101 \\
\hline pKF107 & pDL2 & -59 to +30 region of $f t s Z A \mathrm{P} 1$ & FKF107, FKR101 \\
\hline pKF101 & pDL2 & -45 to +30 region of $f t s Z A$ P1 & FKF108, FKR101 \\
\hline pETYycF & pET15b & Entire coding region of $y y c F$ ( 1 to 711 ) & FKF301, FKR301 \\
\hline
\end{tabular}

* Numbers in parentheses indicate the nucleotide numbers of each gene.

†Primers used to PCR-amplify the inserts.

Northern blot analysis. B. subtilis 168 cells were collected by centrifugation at various time points during growth in the sporulation medium. Each cell pellet (cell density $10 \mathrm{OD}_{600}$ units) was resuspended in $1 \mathrm{ml} \mathrm{SET} \mathrm{buffer}(50 \mathrm{mM}$ Tris/ $\mathrm{HCl}$ $\mathrm{pH} 7 \cdot 6,50 \mathrm{mM}$ EDTA, $20 \%$ sucrose) containing $2 \mathrm{mg}$ lysozyme, and kept on ice for $10 \mathrm{~min}$. Cells were then collected and treated with ISOGEN (Nippon Gene) to prepare RNA fractions. Ten micrograms of total RNA was loaded into each lane of a $1 \%(\mathrm{w} / \mathrm{v})$ agarose gel. After electrophoresis, RNA was blotted on a positively charged nylon membrane (Hybond- $\mathrm{N}^{+}$, Amersham Life Science). Digoxigenin (DIG)labelled antisense RNA probes encompassing each of the $y y c F G H I J$ and $y y x A$ genes were prepared in vitro with $\mathrm{T} 7$ RNA polymerase using PCR products as templates. Inserts of the pKF001, pKF002, pKF003, pKF004, pKF005 and pKF006 plasmids were amplified with T3T7R, which contains the T7 promoter sequence, and $\mathrm{T} 3 \mathrm{~F}$, and used as templates for in vitro RNA synthesis using the DIG RNA Labelling Kit (Boehringer Mannheim). Hybridization and detection of the signals were done following the manufacturer's instructions (Boehringer Mannheim).

Fluorescence microscopy. Cell morphology and nucleoid distribution were examined by fluorescence microscopy after DAPI staining, as described by Hassan et al. (1997).

$\boldsymbol{\beta}$-Galactosidase assay. B. subtilis cells growing in LB medium $\left(\mathrm{OD}_{600} 0 \cdot 4\right)$ were collected by centrifugation and the activity of the $\beta$-galactosidase was assayed according to Youngman et al.
(1985). One unit was defined as $1 \mathrm{nmol}$ 4-methylumbelliferyl $\beta$-D-galactoside hydrolysed in $1 \mathrm{~min}$ per mg protein. Protein concentration was determined using the Bio-Rad Protein Assay Kit. All results are the means of three or more assays.

Two-dimensional PAGE and micro-sequencing of proteins. B. subtilis cells grown in $200 \mathrm{ml} \mathrm{LB}$ medium were harvested at $\mathrm{OD}_{600} 0 \cdot 4$, and washed with $10 \mathrm{mM}$ Tris $/ \mathrm{HCl}(\mathrm{pH} 8 \cdot 0)$ followed by $10 \mathrm{mM}$ Tris $/ \mathrm{HCl}(\mathrm{pH} \mathrm{8.0)}$ containing $10 \%$ sucrose. The cells were then resuspended in $10 \mathrm{mM}$ Tris $/ \mathrm{HCl}$ (pH 8.0) containing $10 \%$ sucrose, $1 \mathrm{mM} \mathrm{PMSF}$ and $1 \mathrm{mg}$ lysozyme $\mathrm{ml}^{-1}$, and incubated at $37^{\circ} \mathrm{C}$ for $10 \mathrm{~min}$, followed by addition of 9 vols lysis solution [8 $\mathrm{M}$ urea, $1 \mathrm{mM}$ DTT, $1 \mathrm{mM}$ PMSF and $1.5 \%$ IPG phor (Pharmacia Biotech)]. After removal of insoluble materials by centrifugation at $18000 \mathrm{~g}$ for $15 \mathrm{~min}$ at $25^{\circ} \mathrm{C}$, protein mixtures were isoelectrophoretically focused at room temperature on $180 \mathrm{~mm}$ IPG Drystrip pH 4-7, using the Multiphor II 2-D system and following the manufacturer's instructions (Pharmacia Biotech). The second dimension was run using a precast $12-14 \%$ gradient gel (Pharmacia Biotech). Proteins separated by two-dimensional PAGE were electroblotted onto a PVDF membrane (Bio-Rad) and the $\mathrm{N}$-terminal sequences were determined using a 470A automated gas-phase sequencer (PE Biosystems).

Purification of the $\mathrm{His}_{6}$-YycF protein. E. coli BL21(DE3)pLysS cells (Novagen) containing the pETYycF plasmid were incubated at $30^{\circ} \mathrm{C}$ in $10 \mathrm{ml} \mathrm{LB}$ medium containing ampicillin 
Table 3. Primers used in this study

\begin{tabular}{|c|c|c|}
\hline Primer & Sequence* & $\begin{array}{l}\text { Location in } \\
\text { B. subtilis } 168 \\
\text { chromosome } †\end{array}$ \\
\hline FKF001 & cgaggcagatctAGTAGATGATGAAAAACC & $4153590 \ldots 4153573$ \\
\hline FKR001 & cgaggcagatctgaattcTCTGAATCCTTAGCCGTC & $4153357 \ldots 4153374$ \\
\hline FKF002 & cgaggcagatctGTCGATCCAATTTAAGATTAC & $4152872 \ldots 4152852$ \\
\hline FKR002 & cgaggcagatctgaattcCATACTCGCGACAACGTAG & $4152386 \ldots 4152404$ \\
\hline FKF003 & cgaggcagatctCGATATTACTTACGGTAC & $4151048 \ldots 4151031$ \\
\hline FKR003 & cgaggcagatctgaattcGTATTCAAACGACTGATTAG & $4150624 \ldots 4150643$ \\
\hline FKF004 & cgaggcagatctCAATCTTCATCGTTGCC & $4149694 \ldots 4149678$ \\
\hline FKR004 & cgaggcagatctgaattcACAAGTGCCTGAGCATCG & $4149346 \ldots 4149363$ \\
\hline FKF005 & cgaggcagatctCGTACTTGCGAGCGGGAG & $4148835 \ldots 4148818$ \\
\hline FKR005 & cgaggcagatctgaattcGCCGCATCGTGGGAAACG & $4148476 \ldots 4148493$ \\
\hline FKF006 & cgaggcagatctACGAACGTGAGGAAGAAC & $4147967 \ldots 4147950$ \\
\hline FKR006 & cgaggcagatctgaattcCCCAGACTTCACTTTATCTGA & $4147423 \ldots 4147443$ \\
\hline FKF011 & cgaggcagatctCCATTCTTTACATGGGCC & $4153693 \ldots 4153676$ \\
\hline FKF012 & cgaggcagatctGAGAAACCCAGAACAGGAC & $4152924 \ldots 4152906$ \\
\hline FKF021 & tgtaaaacgacggecagtaggatccGGCAAACATGAGGAGTG & $4153943 \ldots 4153927$ \\
\hline FKR021 & cgaggcagatctGGGCATTAGTCCTGTTCTG & $4152898 \ldots 4152916$ \\
\hline FKR022 & CCGTCTTTATTTGGGAGCATAATATGTAAAAGAATTAAATCAGGC & $4153429 \ldots 4153473$ \\
\hline FKF022 & GCCTGATTTAATTCTTTTACATATTATGCTCCCAAATAAAGACGG & $4153473 \ldots 4153429$ \\
\hline FKF101 & ttttcggtgagaattcAGCCACATTCATTGTATTGTTGTTCC & $1595797 \ldots 1595822$ \\
\hline FKF102 & ttttcggtgagaattcTTACACACTTGTAAAGCCACATTCATTGTATTGTTGTTCC & $1595783 \ldots 1595822$ \\
\hline FKF103 & cggtgagaattcTCTGTTGTTATTTTTTGTTACACAC & $1595766 \ldots 1595790$ \\
\hline FKF104 & cggtgagaattcAAGCACATAAAAATATTCTGTTG & $1595750 \ldots 1595772$ \\
\hline FKF105 & cggtgagaattcAAACATAAAATGTGAAAAGCAC & $1595734 \ldots 1595755$ \\
\hline FKF106 & cggtgagaattcTTTTCAATAAACATAAAATGTGAAAAGC & $1595726 \ldots 1595753$ \\
\hline FKF107 & cggtgagaattcGGATATAACGAATATTTTCAATAAAC & $1595712 \ldots 1595737$ \\
\hline FKF108 & cggtgagaattcTATACATAGGATATAACGAATATTTTC & $1595704 \ldots 1595730$ \\
\hline FKR101 & cgaggcagatctCATTCTATGGCACCTCCTC & $1595872 \ldots 1595854$ \\
\hline FKF201 & AAAAAAATGTGATATAAAAGAGG & $1595680 \ldots 1595702$ \\
\hline FKR201 & AATGAATGTGGCTTTACAAG & $1595809 \ldots 1595790$ \\
\hline FKF203 & GAAATGGTATTTGTTTCCGG & $1595493 \ldots 1595512$ \\
\hline FKR203 & AAATACAAGTCTACACCAAG & $1595565 \ldots 1595584$ \\
\hline $\mathrm{T} 3 \mathrm{~F}$ & TGTAAAACGACGGCCAGTTTGTGAGCGGATAACAATTA & (pMutinT3) \\
\hline T3T7R & $\begin{array}{l}\text { CAGGAAACAGCTATGACCTAATACGACTCACTATAGGGCGAGTGTATCAACAAGCT } \\
\text { GGGGATC }\end{array}$ & (pMutinT3) \\
\hline FKF301 & tgtaaaacgacggccagtcatatgATGGATAAAAAGATCCTTGTAG & $4153610 \ldots 4153589$ \\
\hline FKR301 & caggaaacagctatgaccctcgagCATTAGTCCTGTTCTGGG & $4152901 \ldots 4152918$ \\
\hline pDLF & tgtaaaacgacggccagtCTTGATAATAAGGGTAAC & (pDL2) \\
\hline
\end{tabular}

*Underlining indicates artificial recognition sites of restriction enzymes. Bold and lower-case characters indicate mutations and artificial sequences, respectively.

† Numbers were according to http://bacillus.genome.ad.jp/BSORF-DB.html.

$\left(50 \mu \mathrm{g} \mathrm{ml}^{-1}\right)$. When the culture reached an $\mathrm{OD}_{600}$ of $0 \cdot 6$, IPTG was added to a final concentration of $1 \mathrm{mM}$. The cells were incubated for another $3 \mathrm{~h}$, then harvested by centrifugation, and the $\mathrm{His}_{6}-\mathrm{YycF}$ protein was purified according to the manual of the PET system (Novagen). Collected cells were washed with a binding buffer $(0.5 \mathrm{M} \mathrm{NaCl}, 5 \mathrm{mM}$ imidazole, $20 \mathrm{mM}$ Tris/ $\mathrm{HCl} \mathrm{pH} \mathrm{7.9),} \mathrm{and} \mathrm{resuspended} \mathrm{in} 25 \mathrm{ml}$ of the same buffer. The cells were broken by sonication on ice, and the lysate was centrifuged at $39000 \mathrm{~g}$ for $30 \mathrm{~min}$ at $4{ }^{\circ} \mathrm{C}$. The supernatant fraction was loaded on the His-Bind Resin, and the resin was washed with $10 \mathrm{ml}$ of the binding buffer followed by $10 \mathrm{ml}$ of a washing buffer $(0.5 \mathrm{M} \mathrm{NaCl}, 60 \mathrm{mM}$ imidazole, $20 \mathrm{mM}$ Tris/ $\mathrm{HCl} \mathrm{pH} 7 \cdot 9$ ). Protein bound to the resin was eluted with $10 \mathrm{ml}$ each of the binding buffers containing an increasing amount of imidazole $(0 \cdot 1$ to $1 \mathrm{M})$. The fraction containing $\mathrm{His}_{6}-\mathrm{YycF}$ protein was stored at $-80^{\circ} \mathrm{C}$ after the addition of glycerol to $10 \%(\mathrm{v} / \mathrm{v})$.

Gel mobility-shift assay. DNA fragments covering the -168 to -35 region of the fts AZ P1 promoter and the -92 to +1 region of the fts $A Z \mathrm{P} 3$ promoter were PCR-amplified, using primer sets FKF201-FKR201 and FKF203-FKR203, respectively. DNA fragments covering the -59 to $-35,-77$ to -35 and -92 to -35 regions of the P1 promoter were PCRamplified from plasmids pKF105, pKF106 and pKF107, respectively, using primer set pDLF-FKR201. PCR products were purified using TaKaRa RECOCHIP (Takara) after 
separation in agarose gel, and end-labelled with DIG using the DIG Labelling Kit (Boehringer Mannheim). The binding reactions ( $10 \mu \mathrm{l}$ final volume) were performed by incubating 20 fmol each of the DIG-labelled DNA fragments, $0.5 \mu \mathrm{g}$ poly(dIdC) and 0-24 pmol purified $\mathrm{His}_{6}-\mathrm{YycF}$ protein in $50 \mathrm{mM}$ PIPES (pH 6.1), $200 \mathrm{mM} \mathrm{NaCl}, 1 \mathrm{mM}$ EDTA, $4 \mathrm{mM} \mathrm{MgCl}{ }_{2}$, $4 \mathrm{mM}$ DTT, $0.5 \%$ Tween 20 and $10 \%$ (v/v) glycerol. For binding competition assays, $20 \mathrm{pmol}$ unlabelled fragment was added to the reaction mixture. After incubation at $25^{\circ} \mathrm{C}$ for $30 \mathrm{~min}, 2 \mu \mathrm{l}$ loading dye $(0 \cdot 1 \%$ xylene cyanol in $40 \%, \mathrm{v} / \mathrm{v}$, glycerol, $22.25 \mathrm{mM}$ Tris, $20 \mathrm{mM}$ boric acid and $0.5 \mathrm{mM}$ EDTA, pH 8.0) was added to stop the reactions and the samples were loaded on $5 \%$ polyacrylamide nondenaturing gels (29:1 acrylamide to bisacrylamide in 0.5 $\times$ TBE buffer). After electrophoresis, DIG-labelled DNA fragments were transferred onto a Hybond-N + membrane (Amersham Life Science) and detected using the DIG Gel Shift Assay Kit (Boehringer Mannheim).

\section{RESULTS}

\section{Characterization of an operon containing yycF and yycG}

The nucleotide sequence around the $y y c F$ and $y y c G$ genes suggested that they constitute an operon with additional four genes, $y y c H, y y c I, y y c J$ and $y y x A$ (Ogasawara et al., 1994; Fig. 1a). Northern blot analysis using the $y y c F$ - and $y y x A$-specific RNA probes revealed a common $7.4 \mathrm{~kb}$ transcript covering six genes in the early vegetative growth phase (Fig. 1b, c). The same transcript was detected with the $y y c G-, y y c H-, y y c l-$ and $y y c J$-specific probes (data not shown). In addition, the $y y c F$ probe detected a $2.4 \mathrm{~kb}$ transcript in the early vegetative phase and the $y y x A$ probe a $1.4 \mathrm{~kb}$ transcript in the late sporulation phase.

To characterize functions of $y y c F G H I J$ and $y y x A$ genes, we attempted to knock out each of them by integrating the pMutinT3 plasmid harbouring an internal fragment of each gene into the genome by a Campbell-type recombination (Vagner et al., 1998). Knockout mutants of $y y c H, y y c l, y y c J$ and $y y x A$ were easily obtained, and growth defects, including the formation of heat-resistant spores, were not observed in the mutants (data not shown). By contrast, $y y c F$ and $y y c G$ disruptants could not be obtained, suggesting that $y y c F$ and $y y c G$ are essential for cell growth. Therefore, we constructed conditional-null mutants by integrating pMutinT3 harbouring the SD sequence and the $\mathrm{N}$-terminal portion of $y y c F$ or $y y c G$ (Fig. 2a). If these genes are indeed essential, integration of the plasmids was expected to occur only in the presence of IPTG, where the expression of $y y c F$ and $y y c G$ would be maintained by an IPTGinducible promoter, Pspac. As expected, transformants in which the pMutinT3 derivatives were properly integrated into the genome (NIS8033 and NIS8032) were obtained in the presence, but not in the absence, of IPTG.

The growth of the conditional-null mutant of $y y c F G$ (NIS8033) was monitored in liquid LB medium, with and without IPTG (Fig. 2b). When IPTG was removed from the medium, the increase in optical density halted within $2 \mathrm{~h}$ and cells began to lose viability. Similar

(a)

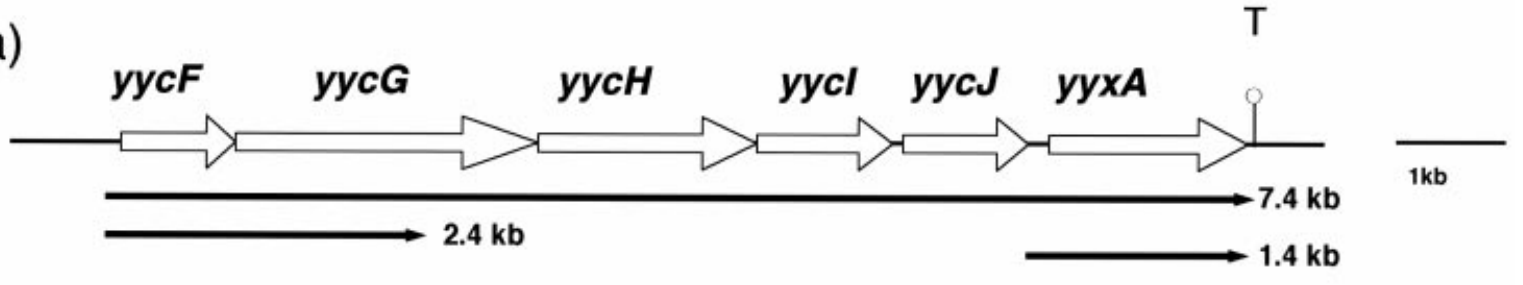

(b)

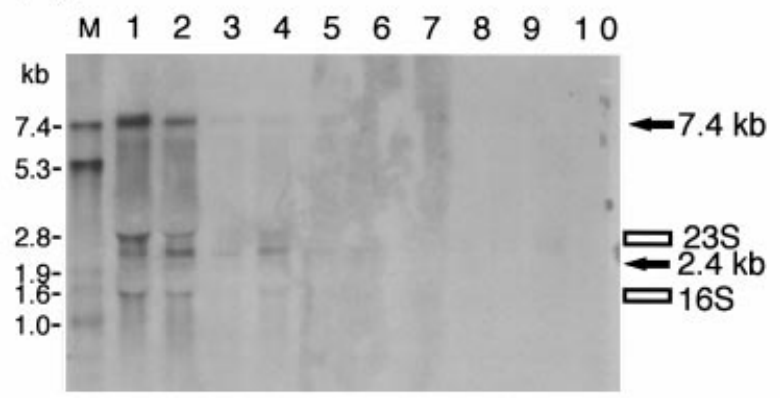

(c)

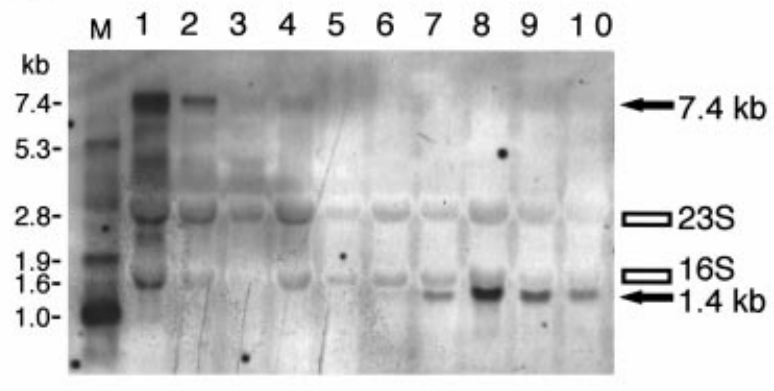

Fig. 1. Gene organization and transcriptional units of the $y y c F G H I J$ and $y y x A$ region. (a) Arrangement of the $y y c F G H I J$ and $y y x A$ genes is shown schematically. $T$ indicates the location of a possible rho-independent termination signal of transcription. Below the map, transcripts detected by Northern blot analysis are indicated by arrows. (b, c) Northern blot analysis with yycF- (b) and yyxA-specific (c) RNA probes. Each lane contained $10 \mu \mathrm{g}$ total RNA from the $B$. subtilis wildtype strain 168 at $t_{-2.5}$ (lane 1), $t_{-2}(2), t_{-1.5}(3), t_{-1}(4), t_{0}(5), t_{1}(6), t_{2}(7), t_{3}(8), t_{4}(9)$ and $t_{5}$ (10) during growth in sporulation medium. An RNA marker (Boehringer Mannheim) was loaded in lane $M$ and sizes are indicated on the left of the blots. Positions of rRNA are indicated (23S, $2.93 \mathrm{~kb} 23 \mathrm{~S}$ rRNA; 16S, 1.55 kb 16S rRNA). 
(a)

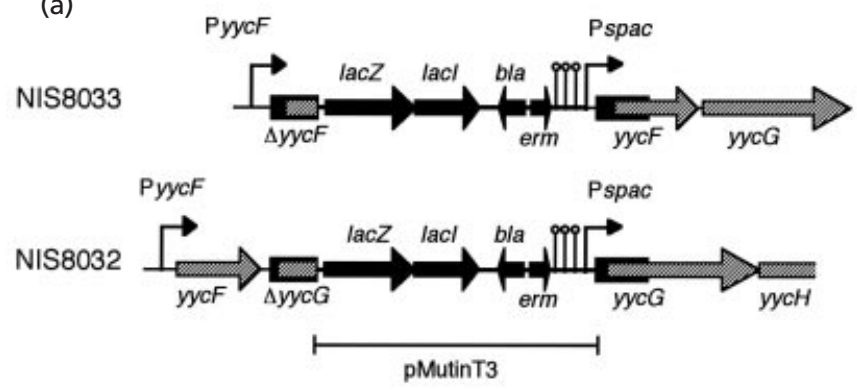

(b)

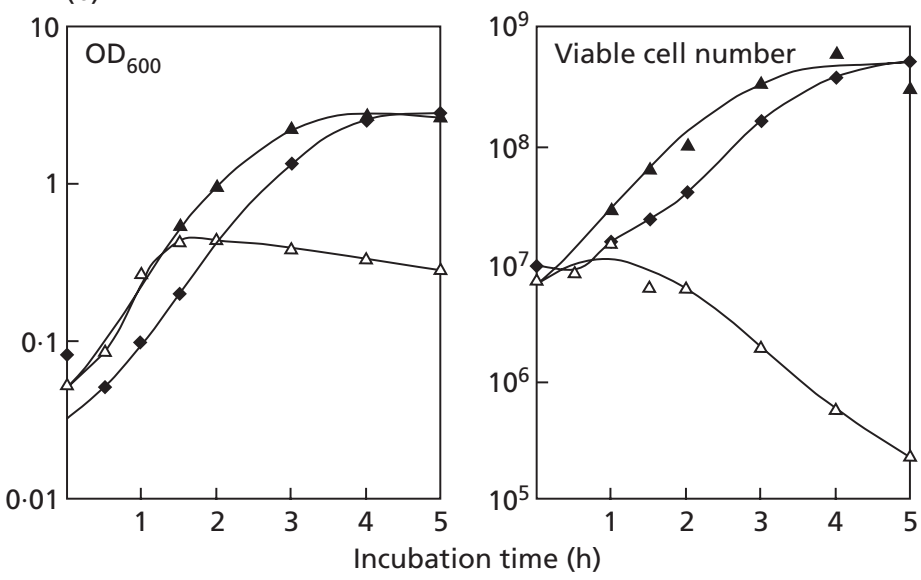

(c)
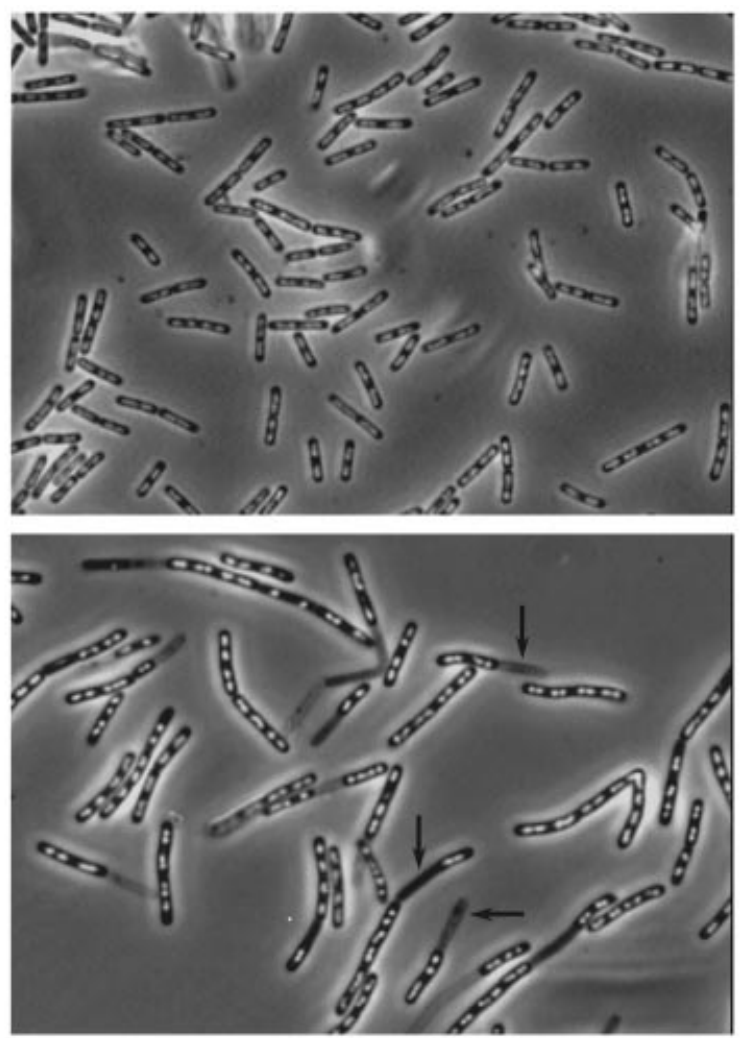

Fig. 2. IPTG-dependent growth of the conditional-null mutant of yycFG. (a) Structures of conditional-null mutants of yycFG (NIS8033) and yycG (NIS8032). Filled and hatched arrows indicate genes on the pMutinT3 plasmid and on the $B$. subtilis genome, respectively. The filled box indicates the region cloned in pKF011 or pKF012. (b) $\mathrm{OD}_{600}$ and viable cell number (colony formation on LB plates with IPTG per ml culture) of NIS8033 in liquid LB medium with ( $\boldsymbol{\Delta}$ ) and without IPTG $(\triangle)$ were monitored after inoculating the cells at time 0 from an overnight culture with IPTG. As a control, both parameters of the wild-type 168 in the absence of IPTG are indicated ( $\diamond)$. (c) DAPI-stained images of wild-type 168 (upper) and NIS8033 cells (lower) after incubation for $2 \mathrm{~h}$ in the absence of IPTG. Cells in which the cytoplasmic contents appear to have been lost are indicated by arrows.

growth defects were also observed in both the sporulation and a defined salt medium (data not shown). Microscopic examination of the mutant cells cultivated for $2 \mathrm{~h}$ in the absence of IPTG revealed the presence of ghost cells in which the cytoplasmic contents seemed to be lost (Fig. 2c). Fabret \& Hoch (1998) reported the same phenomenon for the $y y c F$-ts mutant at the nonpermissive temperature. The defect of growth was not clearly observed for the Pspac-yycG mutant (NIS8032) in liquid medium without IPTG, suggesting that a weak residual expression of $y y c G$ from Pspac in the absence of IPTG would be sufficient to maintain apparently normal cell growth for several generations (data not shown).

\section{Inactivation of the yycG sensor gene in the presence of a mutated YycF regulator}

We then asked if the growth defect in the YycG sensor mutant was due to a deficiency in activation of the $\mathrm{YycF}$ regulator. A $1046 \mathrm{bp}$ fragment covering the promoter and the complete coding region of the $y y c F$ gene was cloned into a shuttle plasmid, pRB373 (Bruckner, 1992), and a mutation which replaced the conserved Asp residue (Asp-54, probable phosphorylation site) with His was introduced by site-directed mutagenesis (pRBYycFD54H, Fig. 3a). We then transformed cells carrying pRBYycFD54H by the pMutinT3-yycG plasmid (pFK002), and inactivated the $y y c G$ sensor gene (Fig. 3b). This finding indicated that the YycFD54H protein was locked in an active form independently of the YycG kinase. Furthermore, this evidence strongly suggested a direct interaction between the YycG kinase and the $\mathrm{YycF}$ regulator. The growth defect in the absence of $\mathrm{YycG}$ is attributed to a deficiency in activation (phosphorylation) of the $\mathrm{YycF}$ regulator.

\section{Overproduction of the YycF regulator induces excess cell division}

The copy number of pRB373 in B. subtilis was reported to be about 50 (Bruckner, 1992). Thus, the YycF or YycFD54H protein was expected to be overproduced within cells carrying pRBYycF or pRBYycFD54H, and this was confirmed by two-dimensional PAGE analysis of whole-cell extracts (Fig. 4a). The molecular mass and pI value of the $\mathrm{YycF}$ protein were calculated to be 
(a)

$y y c F$

48 ProAspLeuIleLeuLeuAspIleMetLeuProAsnLysAsp 61 141 GCCIGATTTAATICTITTTAGATATTATGCTCCCAAATAAAGACGG 182

FKF022

FKR022

5 ' - GCCTGATTTAATTCTTTTACATATTATGCTCCCAAATAAAGACGG -3'

3'- CGGACTAAATTAAGAAAATGIATAATACGAGGGITTATITCTGCC -5' His

(b)

Plasmid in the cell

Number of transformants

\begin{tabular}{lc}
\hline none & 5 \\
pRB373 & 2 \\
pRBYycF & 0 \\
pRBYycFD54H & $1.2 \times 10^{2}$ \\
\hline
\end{tabular}

Fig. 3. Inactivation of the $y y c G$ sensor gene in the presence of a mutated YycF regulator, YycFD54H. (a) Design of primers, FKR022 and FKF022, used to introduce a base change that replaces Asp-54 of the YycF protein with His. The partial nucleotide sequence and the deduced amino acid sequence of $y y c F$, containing the XXXXD motif ( $X$ indicates non-polar residues, underlined) conserved in response regulators (Parkinson \& Kofoid, 1992), are shown. Nucleotide sequences of FKR022 and FKF022 primers are shown below. (b) Wild-type 168 and its derivatives harbouring pRB373, pRBYycF or pRBYycFD54H were transformed with pKF002 containing an internal fragment of yycG. The number of erythromycinresistant transformants (disruptants of $y y c G$ ) per $\mathrm{ml}$ of competent cells is shown.
$27 \cdot 4 \mathrm{kDa}$ and $5 \cdot 06$, respectively. In cells harbouring pRBYycF, the intensity of a spot with an apparent molecular mass of $31 \mathrm{kDa}$ and pI value of $5 \cdot 15$ markedly increased compared with that of the cells harbouring the pRB373 vector. The $\mathrm{N}$-terminal 12 amino acid sequence of the protein in the spot perfectly matched that deduced from the nucleotide sequence of the $y y c F$ gene (data not shown). In cells harbouring pRBYycFD54H, there was an additional intense spot with a slightly higher $\mathrm{pI}$ value, and the $\mathrm{N}$-terminal amino acid sequence was again identical to that of $\mathrm{YycF}$ (data not shown).

When cells carrying pRBYycF or pRBYycFD54H were examined by phase-contrast microscopy, we noticed production of mini-cells (Fig. 4b). The proportion of mini-cells was calculated to be $4.8 \%$ (49 mini-cells $/ 1020$ cells observed) and $2.9 \%(31 / 1080)$ for cells harbouring pRBYycF and pRBYycFD54H, respectively. By contrast, only two mini-cells $(0 \cdot 2 \%)$ were found among 1074 cells harbouring pRB373. Furthermore, statistical analysis of cell length revealed that the overproduction of the $\mathrm{YycF}$ or YycFD54H protein resulted in shorter cells (Fig. 4c). Therefore, excess cell division was suggested to occur in cells carrying pRBYycF or pRBYycFD54H.

\section{Overproduction of the YycF regulator stimulates expression from the P1 promoter of the ftsAZ operon}

The observation described above suggested that the overproduced $\mathrm{YycF}$ regulator promoted the expression (a)

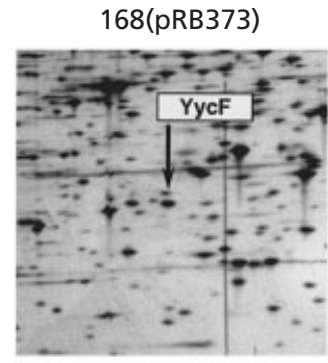

(b)

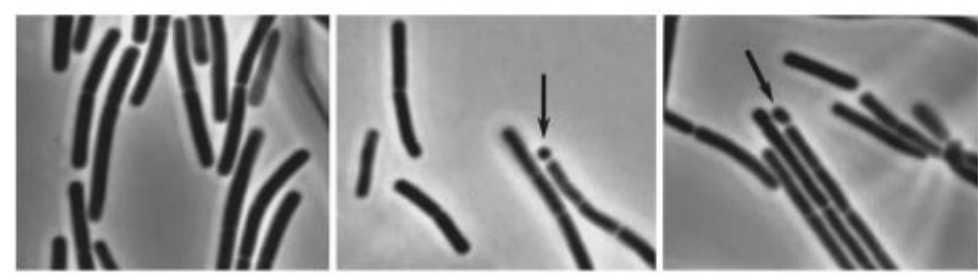

(c)

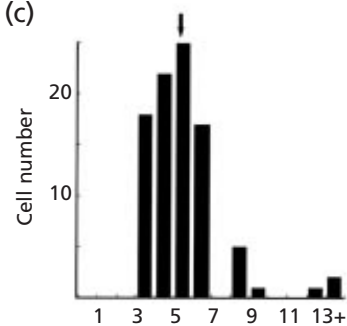

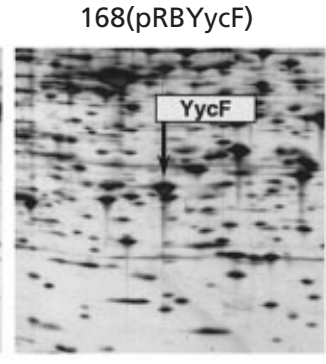
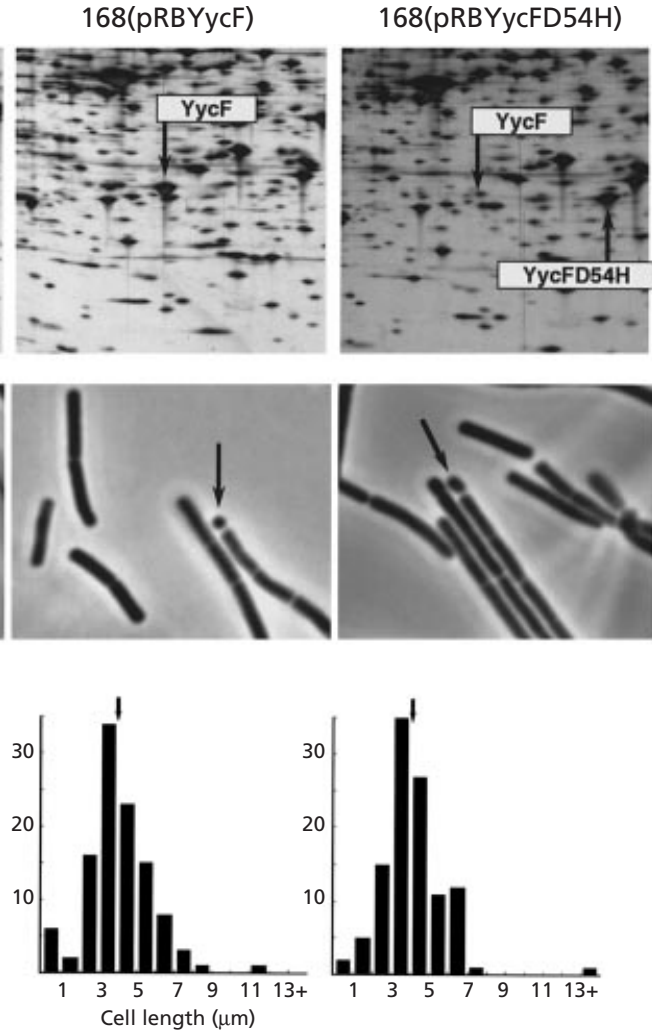

Fig. 4. Effects of $\mathrm{YycF}$ and YycFD54H overproduction on cell size. (a) $B$. subtilis 168 cells harbouring pRB373, pRBYycF or pRBYycFD54H in LB medium were harvested in the vegetative growth phase $\left(O_{600} 0.4\right)$ and crude extracts were analysed by twodimensional PAGE. Gels were stained using the Pharmacia Biotech Silver Staining Kit. Parts of two-dimensional gels including YycF and YycFD54H spots are shown. (b) Phasecontrast images of 168 cells harbouring pRB373, pRBYycF or pRBYycFD54H. Minicells are indicated by arrows. (c) Histograms showing the frequency distribution of cell length of each strain. About 100 cells from the each strain were measured. The mean cell length was $5.6 \mu \mathrm{m}, 4.1 \mu \mathrm{m}$ and $4.1 \mu \mathrm{m}$ for cells carrying pRB373, pRBYycF and pRBYycFD54H, respectively (indicated by the vertical arrows in each panel). 
(a)

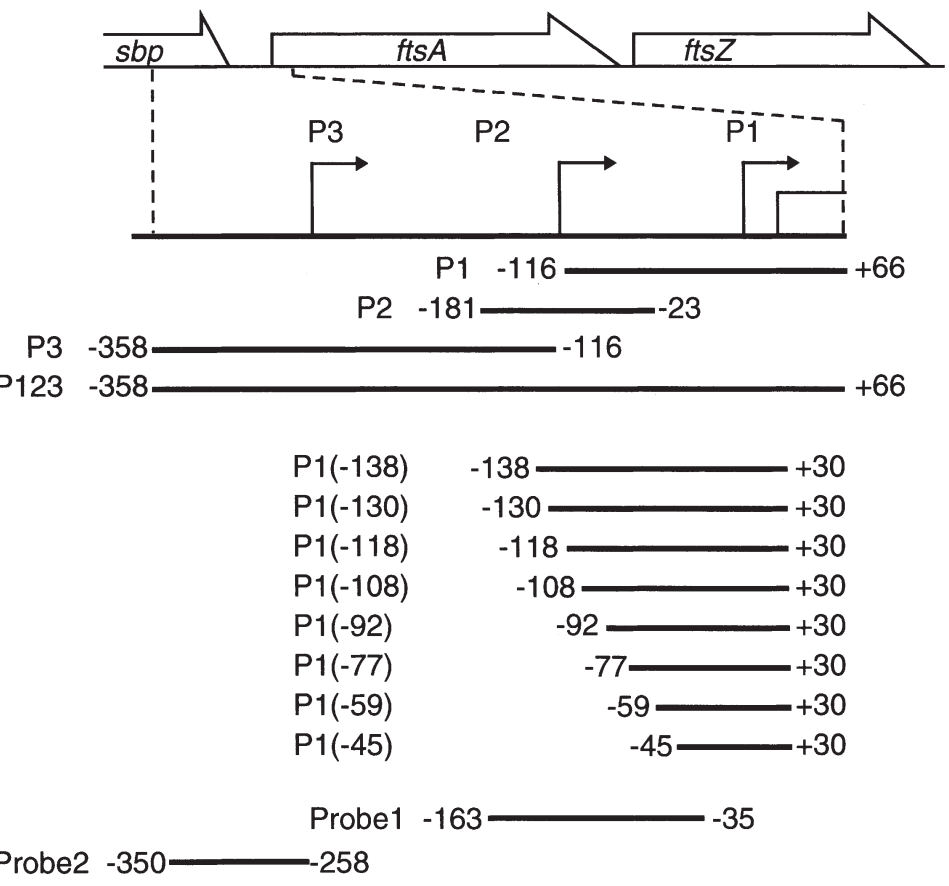

(b)

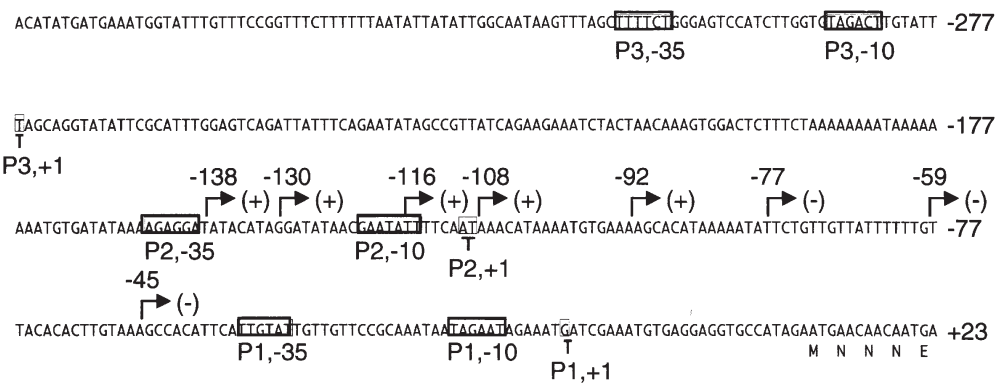

ACTTTACGTCAGTCTTGACCTCGGT +66 $L Y V S L D L G$
Fig. 5. Structure of the $B$. subtilis ftsAZ operon. (a) The organization of the ftsA and $f t s Z$ genes and their promoters are schematically shown (Gonzy-Treboul et al., 1992). Below the map, DNA fragments transcriptionally fused to the lac $Z$ reporter are shown by bars. DNA fragments used in the gel mobility-shift assay are also shown. Nucleotide numbers of the boundaries of the fragments are indicated. Nucleotide number +1 corresponds to the transcriptional start site from the P1 promoter. (b) Nucleotide sequence of the ftsAZ promoter region. Nucleotide numbering is the same as in (a). In addition to -10 and -35 sequences of the fts $A Z$ promoters, the end-points of the DNA fragments used for the lac $Z$ assays shown in Fig. 7 are indicated. of cell-division gene(s). Therefore, we analysed the effect of YycF overproduction on expression of an essential cell division operon, $f t s A Z$. Three promoter sequences, $\mathrm{P} 1, \mathrm{P} 2$ and $\mathrm{P} 3$, have been identified in the B. subtilis ftsZA operon (Fig. 5; Gonzy-Treboul et al., 1992). The $\mathrm{P} 1$ and P3 promoters were sigma-A dependent and active in the vegetative growth phase, whereas the P2 promoter was sigma-H dependent and important for asymmetric cell division at the onset of sporulation. We constructed cells in which P1, P2, P3 or the whole promoter region was placed in front of the lac $Z$ reporter gene at the amyE locus of the genome (Fig. 5), then pRB373, pRBYycF and pRBYycFD54H plasmids were introduced into them. The LacZ activities in the vegetative growth phase of the cells thus constructed indicated clearly that overproduced $\mathrm{YycF}$ or $\mathrm{YycFD} 54 \mathrm{H}$ activates specifically the expression from the P1 promoter about threefold (Fig. 6). As a consequence, an approximately 1.5 -fold increase in the total activity of the three promoters was observed in $\mathrm{YycF}-$ or
YycFD54H-overproducing cells; this would explain the excess division observed in these cells.

\section{Deletion analysis of a regulatory region of the $\mathrm{ftsZA}$ P1 promoter}

To further characterize regulation of expression from the $\mathrm{P} 1$ promoter by the $\mathrm{YycF}$ regulator, we gradually shortened the upstream sequence of the $\mathrm{P} 1$ promoter in the P1-lacZ assay (Fig. 7; see also Fig. 5). The P1 fragment used in the previous assay contained a $118 \mathrm{bp}$ sequence upstream of the start site of the transcription, and the same level of activation by $\mathrm{YycF}$ was observed in cells containing a $16 \mathrm{bp}$ shorter sequence $(-92)$. By contrast, deletion of a further $15 \mathrm{bp}$ abolished the activation (-77), although a basal level of expression from the P1 promoter was maintained. These results indicated that a region between -92 and -77 was essential for activation of the $\mathrm{P} 1$ promoter by the $\mathrm{YycF}$ protein. 


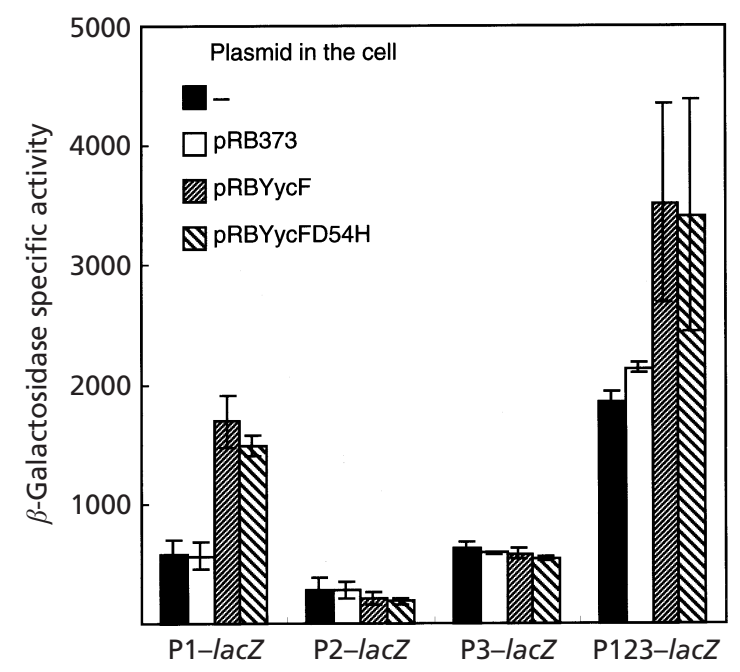

Fig. 6. Effect of $\mathrm{YycF}$ and $\mathrm{YycFD} 54 \mathrm{H}$ overproduction on $\mathrm{fts} A Z$ promoter acitivity. B. subtilis strains containing a P1- (NIS5001), P2- (NIS5002), P3- (NIS5003) or P123-lacZ fusion (NIS5004) were transformed with pRB373, pRBYycF or pRBYycFD54H, cultured in LB medium at $37^{\circ} \mathrm{C}$ to $\mathrm{OD}_{600} \quad 0.4$ and $\beta$-galactosidase activities assayed. All results are the means of three assays, and the error ranges are indicated by vertical lines.

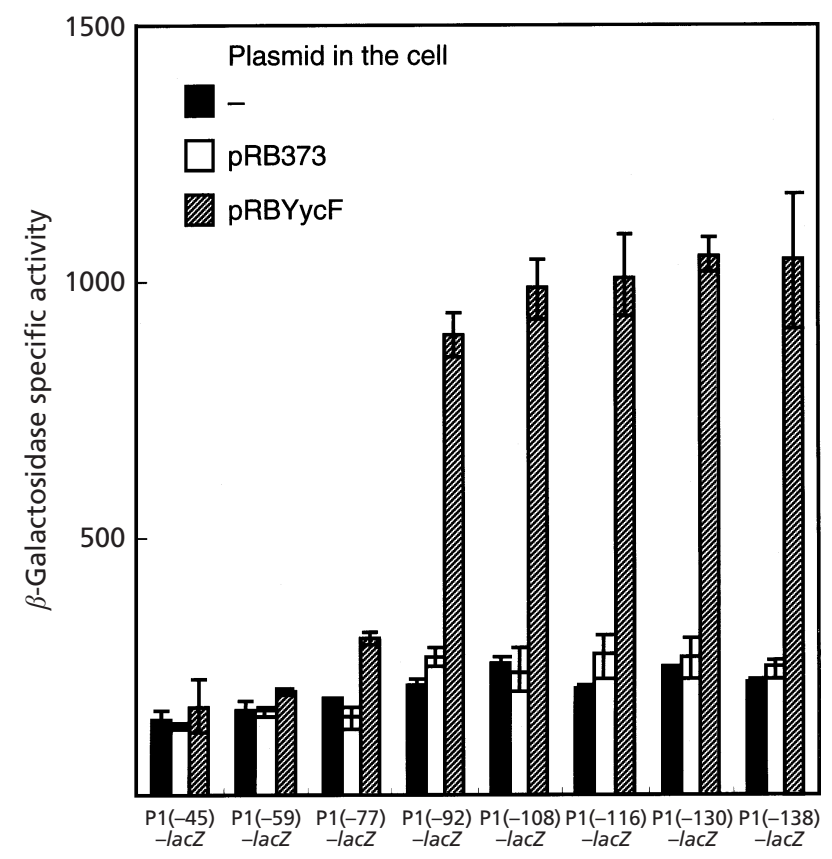

Fig. 7. Deletion analysis of the regulatory sequence by the $\mathrm{YycF}$ regulator. B. subtilis strains containing $\mathrm{P} 1(-138$ to +30$)-$ (NIS5005), P1(-130 to +30)-(NIS5006), P1 $(-118$ to +30$)-$ (NIS5007), P1 $(-108$ to +30$)-($ NIS5008), P1 $(-92$ to +30$)-$ (NIS5009), P1 $(-77$ to +30$)-($ NIS5010), P1 $(-59$ to +30$)-$ (NIS5011) or P1 -45 to +30 )-lacZ (NIS5012) were transformed with pRB373 or pRBYycF. They were cultured in LB medium at $37^{\circ} \mathrm{C}$ to $\mathrm{OD}_{600} 0 \cdot 4$, and the $\beta$-galactosidase activities were assayed. All results are the means of three assays, and error ranges are indicated by vertical lines.

\section{The YycF regulator binds to the $\mathrm{P} 1$ promoter sequence in vitro}

Finally, we examined the direct interaction between the YycF protein and the P1 promoter sequence in gel mobility-shift assays. The $\mathrm{YycF}$ protein was expressed in E. coli as a fused protein with a histidine tag $\left(\mathrm{His}_{6}\right.$ ) and purified to near homogeneity as described in Methods (Fig. 8a). A 134 bp fragment covering the P1 promoter and a $92 \mathrm{bp}$ fragment covering the $\mathrm{P} 3$ promoter were PCR-amplified (see Fig. 5), end-labelled with DIG, and used as probes for gel mobility-shift assays (Fig. 8b). When incubated with $20 \mathrm{fmol}$ each of the DIG-labelled DNA fragments, $18 \mathrm{pmol} \mathrm{His}_{6}-\mathrm{YycF}$ caused a complete shift of the P1 but not the P3 fragment (lane 5). Specificity of the interaction of $\mathrm{His}_{6}-\mathrm{YycF}_{\mathrm{y}}$ with the P1 sequence was further tested in competition experiments. When 20 pmol unlabelled P1 fragment was added to the reaction mixture, a clear competition was observed (lane 7). These results demonstrated that the YycF protein bound specifically to the fts AZ P1 promoter sequence. The in vivo deletion analysis of the regulatory sequence for the $\mathrm{P} 1$ activation by $\mathrm{YycF}$ suggested that the -92 to -77 region would be the binding site of $\mathrm{YycF}$. When a fragment covering -92 to -35 of the $\mathrm{P} 1$ sequence was used as probe, the same mobility shift was observed as with the $134 \mathrm{bp} \mathrm{P1}$ fragment (Fig. 8c, lanes 9-12). As expected, deletion of the -92 to -78 region from the probe markedly reduced the binding affinity to $\mathrm{YycF}$ (lane 5-8), and further deletion to -59 completely abolished the $\mathrm{YycF}$ binding (lanes 1-4). Thus the DNA-binding property of the $\mathrm{YycF}$ protein in vitro was in agreement with the result of the deletion analysis of the in vivo regulatory sequence.

The in vitro binding affinity seemed to be relatively low, as about 1000-fold excess molecules of the $\mathrm{His}_{6}-\mathrm{YycF}$ protein were needed for a complete shift, suggesting that our $\mathrm{His}_{6}-\mathrm{YycF}_{\mathrm{c}}$ preparation was in a non-phosphorylated form. We purified YycG kinase, using the His-tag system in E. coli, and attempted to phosphorylate the $\mathrm{YycF}$ regulator in vitro, so far without success. Acetyl phosphate also failed to activate the purified $\mathrm{YycF}$ protein.

\section{DISCUSSION}

The B. subtilis yycF gene encoding a response regulator and its orthologue in S. aureus was found by other researchers to be essential for cell growth (Fabret \& Hoch, 1998; Martin et al., 1999). We obtained supportive evidence for these findings during construction of a knockout mutant bank of genes newly identified in the genome sequence project. Furthermore we found that the $y y c G$ gene could be deleted in the presence of an active form of the $\mathrm{YycF}$ protein, $\mathrm{YycFD} 54 \mathrm{H}$, thereby suggesting direct interactions between $\mathrm{YycG}$ and $\mathrm{YycF}$. The molecular mechanism involved in locking $\mathrm{YycF}$ in the activated form by replacement of Asp-54 with His has yet to be clarified. 


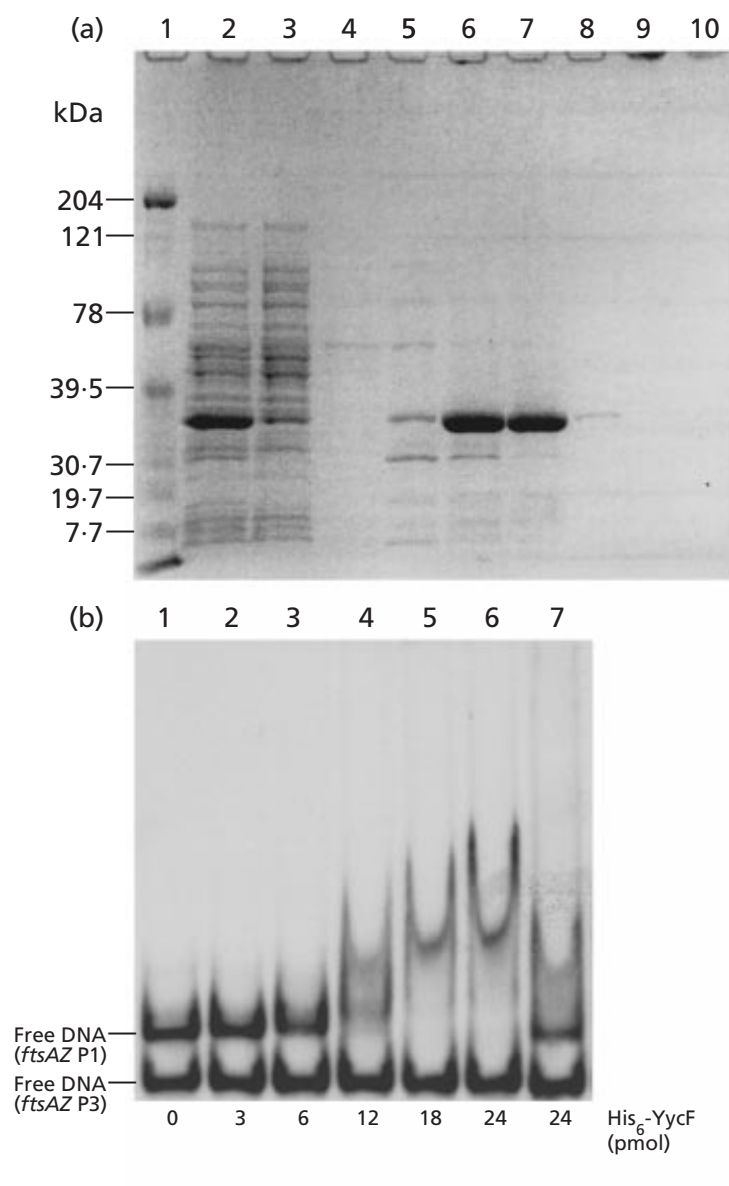

(c) $\quad \begin{array}{llllllllllll}1 & 2 & 3 & 4 & 5 & 6 & 7 & 8 & 9 & 10 & 11 & 12\end{array}$

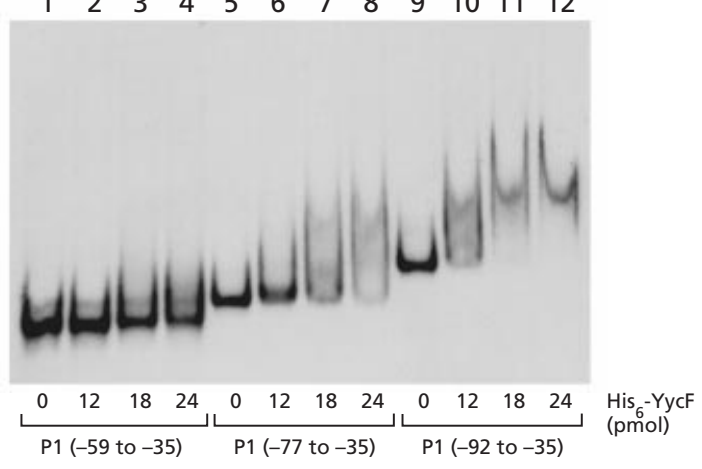

Fig. 8. Direct binding of the YycF regulator to the ftsZA P1 promoter region. (a) SDS-PAGE of protein samples from each purification step of $\mathrm{His}_{6}-\mathrm{YycF}$. The proteins were separated in a $15 \%$ acrylamide gel and stained with Coomassie brilliant blue. Lanes: 1, standard proteins (Bio-Rad), with the molecular masses given on the left; 2 , crude extract; 3 , flowthrough from the nickel resin; 4, wash by $1 \mathrm{mM}$ imidazole; 5 , wash by $30 \mathrm{mM}$ imidazole; 6 , elution by $100 \mathrm{mM}$ imidazole; 7 , elution by $200 \mathrm{mM}$ imidazole; 8, elution by $300 \mathrm{mM}$ imidazole; 9, elution by $400 \mathrm{mM}$ imidazole; 10 , elution by $1 \mathrm{M}$ imidazole. The protein fraction eluted by $100 \mathrm{mM}$ idazole (lane 6) was used for the gel mobility-shift assay. (b) Gel mobility-shift assay for the binding of $\mathrm{His}_{6}-\mathrm{YycF}$ to the P1 and P3 promoter regions. A $134 \mathrm{bp}$ fragment covering the P1 promoter and a $92 \mathrm{bp}$ fragment covering the P3 promoter (see Fig. 5) were endlabelled with DIG. Twenty femtomoles each of the DIG-labelled DNA fragments were incubated with 0 pmol (lane 1), 3 pmol (lane 2), $6 \mathrm{pmol}$ (lane 3), $12 \mathrm{pmol}$ (lane 4), $18 \mathrm{pmol}$ (lane 5) or 24 pmol (lanes 6 and 7) of purified $\mathrm{His}_{6}-$ YycF. Non-labelled P1
The YycFG two-component regulatory system is expected to regulate an essential gene function in $B$. subtilis and $S$. aureus. Based on the observation that overproduction of the $\mathrm{YycF}$ regulator caused excess cell division, we demonstrated that the overproduced $\mathrm{YycF}$ protein stimulated the P1 promoter activity of the celldivision operon $f t s A Z$. Furthermore, we showed that the region between -92 and -77 was essential for the activation of the P1 promoter in vivo, and indeed the YycF protein was shown to bind specifically to the -92 to -59 region of the $\mathrm{P} 1$ sequence in vitro. These results clearly indicate that the essential two-component regulatory system encoded by $y y c F$ and $y y c G$ has the potential to modulate expression of the $f t s A Z$ operon in $B$. subtilis. However, characteristic features in the sequence between -92 and -59 of the P1 promoter remain to be identified.

In E. coli, the expression of $f t s Z$ is controlled by at least six promoters. In addition, at least two transcriptional activators - SdiA, which is a part of a quorum-sensing pathway, and RcsB, which is involved in the regulatory pathway of capsular polysaccharide biosynthesis - have been found to modulate fts $Z$ expression (reviewed by Vicente et al., 1999). In B. subtilis, three promoter sequences for $f t s Z$ expression were identified, and our results show that $\mathrm{YycF}$ is the transcriptional factor with the potential to regulate $f t s Z$ expression. Gonzy-Treboul et al. (1992) reported that the P1 promoter could be deleted without interference with cell growth. We confirmed that the P1 promoter could be deleted, but the resultant cells became elongated, indicating that the P2 and P3 promoters alone are not sufficient to maintain normal cell division (data not shown). However, deletion of a region necessary for $\mathrm{YycF}$ regulation did not clearly affect $\mathrm{P} 1$ promoter activity in wild-type cells (Fig. 7). Therefore, the precise role of the YycFG system under normal expression in the control of cell division awaits further characterization.

The essential nature of the YycFG two-component system cannot be explained solely by its potential to modulate fts AZ expression; it must regulate hitherto unidentified essential gene(s). Alternatively, it may regulate several genes important for cell growth, and simultaneous inhibition of their expression may be lethal. We and others (Fabret \& Hoch, 1998) observed ghost cells that had apparently lost cellular contents by depletion of the B. subtilis YycF protein or by thermal inactivation of the ts-mutant protein. The temperature-

fragment $(20$ pmol) was added to the reaction mixture in lane 7. The samples were run on $5 \%$ polyacrylamide nondenaturing gel and the DIG-labelled fragments were detected using the DIG Gel Shift Assay Kit (Boehringer Mannheim). (c) Deletion analysis of the YycF-binding sequence. DNA fragments covering the -59 to -35 (lanes $1-4$ ), -77 to -35 (lanes $5-9$ ) or -92 to -35 (lanes 9-12) region of the $\mathrm{P} 1$ sequence were labelled with DIG and incubated with 0 pmol (lanes $1,5,9), 12$ pmol (lane 2, $6,10), 18 \mathrm{pmol}$ (lanes 3, 7, 11) or $24 \mathrm{pmol}$ (lanes 4, 8, 12) of purified $\mathrm{His}_{6}-\mathrm{YycF}$. Then the DIG-labelled fragments were separated and detected as described in (b). 
sensitive $y y c F$ mutant of $S$. aureus became hypersensitive to macrolide antibiotics at the permissive temperature, probably due to defects in the permeability barrier (Martin et al., 1999). Based on these observations, we speculate that the YycFG system may perhaps be involved in global regulation of cell envelope synthesis. Further characterization of genes under the control of the YycFG system is essential to determine precise roles in the control of cell growth and to identify the effector molecule that activates the YycFG system. We are currently characterizing the YycF-binding motif in the fts ZA P1 promoter sequence; once the motif is known, we will survey candidate genes that may belong to the $y y c F G$ regulon on the complete genome sequence of $B$. subtilis.

\section{ACKNOWLEDGEMENTS}

We are grateful to Dr Tatsuo Nakayama for determining the $\mathrm{N}$-terminal sequences of $\mathrm{YycF}$ and $\mathrm{YycFD} 54 \mathrm{H}$ proteins. We also thank colleagues in our laboratory for valuable discussions and $\mathrm{M}$. Ohara for language assistance. This work was supported by a Grant-in-Aid for Scientific Research on Priority Areas and a Grant-in-Aid for Scientific Research (C) from the Ministry of Education, Science, Sports and Culture of Japan, and grant JSPS-RFTF96L00105 from the Japan Society for the Promotion of Science.

\section{REFERENCES}

Bruckner, R. (1992). A series of shuttle vectors for Bacillus subtilis and Escherichia coli. Gene 122, 187-192.

Fabret, C. \& Hoch, J. A. (1998). A two-component signal transduction system essential for growth of Bacillus subtilis: implications for anti-infective therapy. J Bacteriol 180, 6375-6383.

Gonzy-Treboul, G., Karmazyn-Campelli, C. \& Stragier, P. (1992). Developmental regulation of transcription of the Bacillus subtilis ftsAZ operon. J Mol Biol 224, 967-979.

Hassan, A. K., Moriya, S., Ogura, M., Tanaka, T., Kawamura, F. \& Ogasawara, N. (1997). Suppression of initiation defects of chromosome replication in Bacillus subtilis dnaA and oriCdeleted mutants by integration of a plasmid replicon into the chromosomes. J Bacteriol 179, 2494-2502.

Jacobs, C., Domian, I. J., Maddock, J. R. \& Shapiro, L. (1999). Cell cycle-dependent polar localization of an essential bacterial histidine kinase that controls DNA replication and cell division. Cell 97, 111-120.
Kasahara, Y., Nakai, S. \& Ogasawara, N. (1997). Sequence analysis of the $36-\mathrm{kb}$ region between gnt $\mathrm{Z}$ and $\operatorname{trn} \mathrm{Y}$ genes of Bacillus subtilis genome. DNA Res 4, 155-159.

Kunst, F., Ogasawara, N., Moszer, I. \& 148 other authors (1997). The complete genome sequence of the gram-positive bacterium Bacillus subtilis. Nature 390, 249-256.

Loomis, W. F., Kuspa, A. \& Shaulsky, G. (1998). Two-component signal transduction systems in eukaryotic microorganisms. Curr Opin Microbiol 1, 643-648.

Martin, P. K., Li, T., Sun, D., Biek, D. P. \& Schmid, M. B. (1999). Role in cell permeability of an essential two-component system in Staphylococcus aureus. J Bacteriol 181, 3666-3673.

Moriya, S., Tsujikawa, E., Hassan, A. K., Asai, K., Kodama, T. \& Ogasawara, N. (1998). A Bacillus subtilis gene-encoding protein homologous to eukaryotic SMC motor protein is necessary for chromosome partition. Mol Microbiol 29, 179-187.

Ogasawara, N. (2000). Systematic function analysis of Bacillus subtilis genes. Res Microbiol 151, 129-134.

Ogasawara, N., Nakai, S. \& Yoshikawa, H. (1994). Systematic sequencing of the 180 kilobase region of the Bacillus subtilis chromosome containing the replication origin. DNA Res 1, 1-14.

Parkinson, J. S. \& Kofoid, E. C. (1992). Communication modules in bacterial signaling proteins. Annu Rev Genet 26, 71-112.

Quon, K. C., Marczynski, G. T. \& Shapiro, L. (1996). Cell cycle control by an essential bacterial two-component signal transduction protein. Cell 84, 83-93.

Schaeffer, P., Millet, J. \& Aubert, J.-P. (1965). Catabolite repression of bacterial sporulation. Proc Natl Acad Sci USA 54, 704-711.

Vagner, V., Dervyn, E. \& Ehrlich, S. D. (1998). A vector for systematic gene inactivation in Bacillus subtilis. Microbiology 144, 3097-3104.

Vicente, M., Chater, K. F. \& De Lorenzo, V. (1999). Bacterial transcription factors involved in global regulation. Mol Microbiol 33, 8-17.

Youngman, P., Perkins, J. \& Sandman, K. (1985). Use of Tn917mediated transcriptional gene fusions to lac $Z$ and cat-86 for the identification and study of regulated genes in the Bacullus subtilis chromosome. In Molecular Biology of Microbial Differentiation, pp. 47-54. Edited by J. A. Hoch \& P. Setlow. Washington, DC: American Society for Microbiology.

Yuan, G. \& Wong, S. L. (1995). Regulation of groE expression in Bacillus subtilis: the involvement of the $\sigma^{\mathrm{A}}$-like promoter and the roles of the inverted repeat sequence (CIRCE). J Bacteriol 177, $5427-5433$.

Received 28 March 2000; accepted 17 April 2000. 